Revista Monografias Ambientais - REMOA v. 14, 2015, p.03-17

EDIÇÃO ESPECIAL: PÓS GRADUAÇÃO EM EDUCAÇÃO,

INTERDISCIPLINARIDADE E TRANSVERSALIDADE

- UNIPAMPA - SÃO GABRIEL - RS

Revista do Centro de Ciências Naturais e Exatas - UFSM, Santa Maria

\title{
Música e Educação Ambiental em uma Escola do Campo localizada no município de São Gabriel - RS: Uma forma interdisciplinar de significar a realidade complexa
}

\author{
Music and environmental education in a Field School in the municipality of São Gabriel - RS: An \\ interdisciplinary way of signifying the complex reality
}

\author{
Cibele Ambrozzi Corrêa ${ }^{1}$, Sônia Conceição Assis de Oliveira², Rafael Cabral Cruz ${ }^{3}$ \\ ${ }^{1}$ Pós Graduanda - Especialização em Educação, Interdisciplinaridade e Transversalidade, UNIPAMPA, SG, RS, Brasil \\ ${ }^{2}$ Pedagoga e Bióloga do Colégio Tiradentes da Brigada Militar de São Gabriel, SG, RS, Brasil. \\ ${ }^{3}$ Oceanógrafo. Professor Doutor da Universidade Federal do Pampa - UNIPAMPA, SG, RS, Brasil
}

\begin{abstract}
Resumo
O antropocentrismo (ser humano como centro do universo), fixado pelo paradigma cartesiano, carrega uma boa parcela de responsabilidade pela crise de percepção quanto ao meio ambiente, visto como objeto de uso, bem como, ao termo Educação Ambiental, entendida tão somente como educação ecológica. A educação possui suas bases apoiadas neste paradigma, o que acarreta na fragmentação das inter-relações de diversos campos do conhecimento. A interdisciplinaridade pode auxiliar na transformação de tal representação isolacionista, por provocar um intenso diálogo entre as áreas, com ações coletivas que visam o todo, entretanto, ainda há resistência em colocá-la em prática nas escolas, devido à complexidade de ser e trabalhar desta forma, tornando-se um desafio aos atores envolvidos por gerar mudanças de comportamentos, paradigmas e, consequentemente, no processo de ensino-aprendizagem. Diante do exposto, buscou-se utilizar a música e a Educação Ambiental, áreas interdisciplinares, em atividades do Macrocampo Acompanhamento Pedagógico do Programa Mais Educação, perpassando os conteúdos curriculares dos anos iniciais do ensino fundamental de uma Escola Rural chamada Escola Municipal de Ensino Fundamental Mascarenhas de Moraes - Polo de São Gabriel/RS, e posteriormente verificar os possíveis efeitos alcançados, através da utilização de uma abordagem qualitativa. Segundo os resultados, ficou evidente a mudança de comportamento e o aumento de interesse dos educandos. Este estudo reúne subsídios que dão embasamento à atuação de novas estratégias educacionais interdisciplinares que podem contribuir para o processo de ensino aprendizagem.
\end{abstract}

Palavras-chave: Ensino-aprendizagem, Interdisciplinaridade, Educação Ambiental, Escola Rural, Música.

\section{Abstract}

The anthropocentrism (human being as center of the universe), set by the Cartesian paradigm, carries a large share of responsibility for the crisis of perception as to the environment, seen as object of use as well, the environmental education, understood only as education ecological. Education has its foundations supported this paradigm, resulting in the fragmentation of the interrelationships of various fields of knowledge. The Interdisciplinary can assist in transforming such isolationist representation, by provoking an intense dialogue between areas, with collective actions aimed at the whole, however, there is still resistance to put it into practice in schools because of the complexity of being and working in this way, making it a challenge to stakeholders for generating behavior change, paradigms and hence the teaching-learning process. Given the above, we sought to use music and environmental education, interdisciplinary areas, in activities of the Macrocampo pedagogical monitoring in the Educational Program More education, passing between curricular contents of early years elementary school of a Rural School Municipal School called elementary school Mascarenhas 
de Moraes - Polo of São Gabriel / RS, and then check the possible effects achieved through using a qualitative approach. According to the results, it became clear behavior change and the increased interest of students. This study brings together subsidies that give foundation to the performance of new interdisciplinary educational strategies that can contribute to the process of teaching and learning.

Keywords: Learning, teaching Interdisciplinary, Environmental Education, Rural School, Music.

\section{Introdução}

Um dos desafios que atores envolvidos no processo de ensino-aprendizagem enfrentam é compreender a realidade escolar de forma interdisciplinar e enxergá-la inserida em um contexto socioambiental que precisa ser levado em consideração neste processo. A educação possui suas bases apoiadas no paradigma cartesiano, tendo ele uma boa parcela de responsabilidade pela representação das relações entre áreas voltadas ao meio ambiente, à natureza e as demais áreas do conhecimento, como aquelas relacionadas ao artístico, social, sociocultural, ser de forma fragmentada. A fragmentação das conexões entre os diversos campos do conhecimento prejudica a compreensão da realidade complexa e, consequentemente, de ser e trabalhar de forma interdisciplinar. O antropocentrismo, ideal cartesiano que considera o ser humano centro do universo, gera uma crise de percepção quanto ao meio ambiente, entendido tão somente como objeto de uso. Grun (1996:44) complementa sobre a influência do modelo cartesiano na educação:

A autonomia do sujeito pensante, livre dos valores da cultura e da tradição, e sua independência do meio ambiente, constituem a própria base da educação e não uma possível deficiência. São como mitos da educação moderna. $\mathrm{O}$ cogito cartesiano é a própria base dessa educação. Tida como um ideal educacional por séculos, esta separação entre o sujeito conhecedor e o objeto [(meio ambiente)] precisa agora ser repensada (GRUN, 1996:44).

O paradigma cartesiano pode ser considerado um obstáculo para promover uma educação holística ${ }^{1}$. Capra (1993, apud GRUN, 1996:64) faz a seguinte observação deste modelo:

Sistemas vivos incluem mais que organismos individuais e suas partes. Eles incluem sistemas sociais - família ou comunidade - e também ecossistemas. Muitos organismos estão não apenas inscritos em ecossistemas, mas são eles mesmos ecossistemas complexos, contendo organismos menores quem têm considerável autonomia e estão integrados harmoniosamente no todo. Todos esses organismos vivos são totalidades cuja estrutura específica surge das interações e interdependências de suas partes (GRUN, 1996:64).

O modelo civilizatório é caracterizado pelo desenvolvimento e uso da tecnologia, pelo cientificismo, pelo capitalismo e pelo excesso no consumo, um estilo de vida em que os bens naturais são tidos com potencial econômico e conhecidos como "recursos naturais", sendo eles adaptados, comercializados e

\footnotetext{
${ }^{1}$ Holístico - do radical grego holos: Significa totalidade. Considerar o todo levando em consideração as partes e suas inter-relações. Disponível em http://www.dicionarioinformal.com.br/hol\%C3\%ADstico/. Acesso em: 10 fev. 2014.
} 
transformados em bens materiais. Os problemas socioambientais da sociedade contemporânea são reflexos deste modelo.

A Educação Ambiental (EA) pode auxiliar na diminuição de tais problemas, através da transformação de visões simplificadas e fragmentadas quanto aos processos e sistemas complexos da relação sociedade-ambiente, por provocar mudanças de comportamentos e valores.

Grun (1996:21) afirma que "a educação ambiental surge hoje como uma necessidade quase inquestionável devido ao fato de que não existe meio ambiente na educação moderna. Tudo se passa como se fossemos educados e educássemos fora de um ambiente", ou seja, como se o processo de ensino-aprendizagem nas escolas, ocorresse paralelo ao meio ambiente. Essa relação isolacionista do homem com o meio é devida ao antropocentrismo, que Grun (1996:44) define como: "o homem é considerado o centro de tudo e todas as demais coisas no universo existem única e exclusivamente em função dele", causando uma crise de percepção ao entender que o ser humano está acima do meio ambiente, resultando na sua autonomia perante a natureza.

Leff (2011:312) afirma que:

Nunca antes na História houve tantos seres humanos que desconhecessem tanto e estivessem tão excluídos dos processos e das decisões que determinam suas condições de existência; nunca antes houve tanta pobreza, tanta gente alienada de suas vidas, tantos saberes subjugados, tantos seres que perderam o controle, a condução e o sentido de sua existência; tantos homens e mulheres desempregados, desenraizados de seus territórios, desapropriados de suas culturas e de suas identidades (LEFF, 2011:312).

Pretende-se, neste estudo, abordar especificamente a experiência ocorrida em uma escola rural, a Escola Municipal de Ensino Fundamental Mascarenhas de Moraes - Polo, localizada no interior da cidade São Gabriel, Rio Grande do Sul, acerca do uso da música e da EA em atividades realizadas na Macroárea Acompanhamento Pedagógico do Programa Federal Mais Educação. Tem-se como problema de pesquisa o seguinte: A música e a EA podem auxiliar no processo de ensino-aprendizagem e na mudança de comportamento do educando?

Para responder esta pergunta, trabalhou-se com a hipótese de que a música e a EA, enquanto processo e quando praticadas no ambiente educacional, abrem novas possibilidades para os estudantes conhecerem outras realidades e outros contextos, provocando-os a desenvolver uma nova forma crítica de pensar, agindo de forma integrada e coletiva, frente aos complexos problemas globais e sociais.

Partindo deste pressuposto, com vista na problemática da crise socioambiental instalada na sociedade, causada muitas vezes pelo desencanto do aprender, do saber e do viver, um dos aspectos justificadores desta pesquisa foi entender quais os efeitos da utilização da música e da EA, campos de conhecimentos interdisciplinares que convergem em diversos pontos, na apreensão de novos conhecimentos, na mudança de comportamento e no aumento do interesse e motivação, ao perpassarem os conteúdos curriculares e inter-relacionarem-se.

\section{Procedimentos Metodológicos}

Neste trabalho utilizou-se como metodologia uma pesquisa bibliográfica, ações interdisciplinares e uma pesquisa de campo. A autora deste trabalho foi responsável pelo desenvolvimento das atividades realizadas no Macrocampo Acompanhamento Pedagógico do Programa Federal "Mais Educação"(TITTON et al., 2011:4), implementado na referida escola, que trata-se de um:

apoio metodológico, procedimentos e materiais voltados às atividades pedagógicas e lúdicas para o ensino e a aprendizagem da Matemática, de práticas de leitura e escrita, de História, de Geografia e das Ciências, contextualizado em projetos de trabalho educacional, de acordo com a 
necessidade e com respeito ao tempo de aprendizado de cada criança, adolescente e jovem (TITTON et al., 2011:4).

Tais atividades realizadas na escola em questão, perduraram do mês de março ao mês de agosto de 2015, e ocorreram com estudantes dos anos iniciais, sendo que, nas terças-feiras, todos que estavam na escola participavam e, nas quartas-feiras, a presença era opcional. Conforme o programa, neste Macrocampo deve-se disponibilizar maior atenção àqueles educandos que apresentem defasagem série/idade em virtude de dificuldades de aprendizagem. Desta forma, optou-se pela formação de turmas multisseriadas, observando a faixa etária, com o intuito de incentivar o convívio e a cooperação entre os mesmos, como forma de motivá-los a aprender e a ensinar, cooperando com os colegas.

Todas as atividades realizadas por este Macrocampo foram voltadas ao aprimoramento da conexão entre os saberes escolares e os saberes locais, articulando com atividades do turno regular e do contraturno, levando em consideração o conhecimento adquirido pelo educando nas atividades propostas, valorizando e incentivando sua participação. As atividades foram realizadas de forma lúdica e interdisciplinar, utilizando principalmente a Educação Ambiental como base fundamental deste processo e a música como ferramenta sensibilizadora e, sempre que possível, as atividades eram embasadas no interesse e na demanda dos educandos, perpassando os conteúdos curriculares.

Para abordar este tema, fez-se necessário articular a pesquisa bibliográfica com a de campo, na perspectiva de uma pesquisa e análise qualitativa, que Malhotra (2006) conceitua sendo como uma "metodologia de pesquisa não-estruturada e exploratória, baseada em pequenas amostras que proporcionam percepções e compreensão do contexto do problema", sendo aplicados questionários com perguntas abertas, que são aquelas que permitem liberdade ilimitada de respostas, podendo conter linguagens próprias dos respondentes, sem influência das respostas pré-estabelecidas pelo pesquisador, visto que o informante poderá escrever aquilo que lhe vier à mente. No total foram vinte e cinco questionários respondidos, sendo sete de pais, quatro de funcionários, sete de professoras e sete de estudantes.

Com esta ferramenta qualitativa, buscou-se verificar a representação social da comunidade escolar em estudo e, para compreender o material coletado, utilizou-se da Análise de Conteúdo de Laurence Bardin (1995:42), que define como:

Um conjunto de técnicas de análise das comunicações visando obter, por procedimentos, sistemáticos e objetivos de descrição do conteúdo das mensagens, indicadores (quantitativos ou não) que permitam a inferência de conhecimentos relativos às condições de produção/recepção [...] destas mensagens (BARDIN, 1995:42).

\section{Educação Ambiental, Música na Escola, Percepção e Representação Social}

\subsection{Educação Ambiental}

O escopo da Educação Ambiental (EA) é fornecer ao ser humano conhecimentos básicos para a compreensão da complexa gama de conexões que regem o meio ambiente, tanto os aspectos bióticos e abióticos, físicos, químicos, biológicos, quanto os sociais, políticos, econômicos, culturais, etc. É um processo consecutivo e interligado de ações (teóricas, metodológicas e práticas) voltadas a todas as esferas da sociedade.

Leff (1999) afirma que:

A educação ambiental interdisciplinar, entendida como a formação de habilidades para apreender a realidade complexa, foi reduzida à intenção de 
incorporar uma consciência ecológica no currículo tradicional (LEFF, 1999: 119).

E ainda que:

A educação ambiental foi reduzida a um processo geral de conscientização cidadã, à incorporação de conteúdos ecológicos e ao fracionamento do saber ambiental a uma capacitação aligeirada sobre problemas pontuais, nos quais a complexidade do conceito de ambiente foi reduzido e mutilado (...) (LEFF, 1999:125).

A EA tornou-se importante por discutir conflitos existentes entre questões sociais e ambientais e pela preocupação quanto aos problemas acarretados pelo uso inadequado dos "recursos naturais". O ato de educar, baseado em preceitos ambientais, trata-se de levar o ser humano a confrontar e a questionar criticamente os diversos valores impostos pela cultura dominante, tornando-se não objeto da prática educativa, e sim, sujeito ativo (GUIMARÃES, 1995:31).

Leff (1999:113) afirma ainda que "a emergência da questão ambiental como problema do desenvolvimento e a interdisciplinaridade como método para um conhecimento integrado são respostas complementares à crise da racionalidade da modernidade". Tendo em vista que muitas ações humanas são predatórias, torna-se imprescindível buscar novas metodologias para minimizar os impactos negativos, e isto interfere principalmente em muitos processos industriais que causam danos ao meio ambiente. Se a ciência e a tecnologia voltarem-se ao sustentável, vão confrontar-se com a complexidade que é o meio ambiente, e terão de alterar suas bases para terem condições de resolver perturbações ambientais complexas, como as diferentes formas de poluição que estão relacionadas ao impacto incitado pela fome e pela miséria.

A problemática ambiental é o reflexo das inter-relações sociedade-ambiente, e devido a isso, seu conhecimento carece de uma abordagem holística e um método interdisciplinar que permitam a conexão das ciências da natureza e da sociedade; do âmbito ideal e do material, da economia, da tecnologia e da cultura (LEFF, 2000:20).

Diante desta afirmativa, pode-se verificar a preocupação quanto à crise instalada pelo modelo civilizatório, que mantém valores e paradigmas nem sempre favoráveis a todas as classes e ao meio ambiente; percebe-se aí a necessidade da EA, que carrega em sua essência a mudança de comportamento perante tais valores, bem como, de novas metodologias que incitem a compreensão da complexidade dos processos socioambientais e a sensibilização dos atores sociais em se enxergar fazendo parte e influenciando tais processos.

\subsection{Música na Escola}

Nos últimos anos, muitas pesquisas surgiram com o intuito de verificar como se dá o processamento musical no cérebro humano. Tal processamento abrange uma série de regiões cerebrais que se correlacionam com a percepção de ritmos, timbres, alturas, melodias, harmonias, e ao mesmo tempo, com a percepção de prazer e de recompensa (MUSZKAT, 2000:70-75). O referido autor afirma que:

A música não apenas é processada no cérebro, mas afeta seu funcionamento. As alterações fisiológicas com a exposição à música são múltiplas e vão desde a modulação neurovegetativa dos padrões de variabilidade dos ritmos endógenos da frequência cardíaca, dos ritmos respiratórios, dos ritmos elétricos cerebrais, dos ciclos circadianos de sono-vigília, até a produção de vários neurotransmissores ligados à recompensa e ao prazer e ao sistema de neuromodulação da dor. Treinamento musical e exposição prolongada à música considerada prazerosa aumentam a produção de neurotrofinas produzidas em nosso cérebro em situações de desafio, podendo determinar 
não só aumento da sobrevivência de neurônios como mudanças de padrões de conectividade na chamada plasticidade cerebral (MUSZCAT, 2000:70-75).

Para Straliotto (2001 apud PEDERIVA; TRISTÃO, 2006:87) a inteligência pode ser desenvolvida por meio da audição, pois conforme o autor:

Cada código sonoro representaria um espaço ativado no cérebro, com a finalidade de reter a informação. Os neurônios que recebem informações codificadas após serem ativados pelos códigos musicais, ficariam "abertos" para receberem conhecimentos de outros órgãos dos sentidos. A ativação dos neurônios seria ampliada à medida que novos conhecimentos vão se somando por meio dos cinco órgãos do sentido (STRALIOTTO, 2001 apud PEDERIVA; TRISTÃO, 2006:87).

A música, percebida através da soma de estímulos sonoros e de atividades manuais, auxilia no desenvolvimento psíquico, bem como no aprimoramento de funções cognitivas. Atua possibilitando conexões de novas informações à bagagem de conhecimentos já existentes, age reacendendo a sensibilidade do educando em se enxergar fazendo parte do meio ambiente, operando tanto na consciência exigente e ativa, quanto na compreensão dos problemas socioambientais existentes, provocando mudanças de comportamento frente a tais problemáticas (PORCHER, 1982).

Sekeff (2007:128) refere-se à música como sendo algo:

Para além da lógica e do pensamento rotineiros, dominando procedimentos libertadores e otimizando funções cognitivas e criativas, a vivência musical que se pretende na educação, não diz respeito apenas aos exercício de obras caracterizadamente belas, assinaladamente bem-feitas, mas sim a todas que motivam o indivíduo a romper pensamentos prefixados, induzindo-o à projeção de sentimentos, auxiliando-o no desenvolvimento e no equilíbrio de sua vida afetiva, intelectual e social, contribuindo enfim para a sua condição de ser pensante (SEKEFF, 2007:128).

Sekeff (2002:14) assegura que a música não se trata tão somente de uma soma de acordes, combinação de sons, pausas e ruídos, mas também se trata de um recurso de expressão, de comunicação, de gratificação, de mobilização, de auto-realização, de catarse, de prazer e sensibilização.

Rocca (2000 apud SEKEFF, 2002:16) afirma que "o artista é o pedagogo da humanidade, pois sua arte provoca nas pessoas, mudanças profundas de mentalidade, atitude, hábito e comportamento que são o grande resultado de todo o processo educativo".

Segundo Schafer (1991:286): [...] "Na educação, e considerando o aspecto da transmissão de conhecimentos, o professor tem todas as respostas, e os alunos a cabeça vazia - pronta para assimilar informações". Entretanto, pode-se observar nos Parâmetros Curriculares Nacionais, concernente ao Meio Ambiente e Saúde, além das convergências existentes entre EA e música, as seguintes recomendações quanto à relação da criança com os recursos disponíveis:

[...] identificar e discutir os aspectos éticos (valores e atitudes envolvidos) e apreciar os estéticos (percepção e reconhecimento do que agrada à visão, à audição, ao paladar, ao tato; de harmonias, simetrias e outros) presentes nos objetos ou paisagens observadas, nas formas de expressão cultural etc (BRASIL, 1998:189).

[...] os alunos descobrem sons nos objetos do ambiente, expressam sua emoção por meio da pintura, poesia, ou fabricam brinquedos com sucata. [...] os professores podem ensinar os alunos a valorizar "produções" de seus colegas 
e respeitá-los em sua criação, suas peculiaridades de qualquer natureza, suas raízes culturais, étnicas ou religiosas. (BRASIL, 1998:190)

Acredita-se que os estímulos sonoros reverberados pela música, poderão auxiliar o educando a desenvolver disposições e aptidões que não se restringem apenas ao domínio da educação musical, pois através da prática ou somente pelo contato com a música, várias regiões cerebrais de ambos os hemisférios são ativadas, levando o educando a apreender e a organizar seus pensamentos e ideias e, a partir do conhecimento de novas informações, aprimorar o saber adquirido, fixá-lo ou reconstruí-lo.

\subsection{Percepção}

A percepção é um processo psicofisiológico através do qual o sujeito seleciona, organiza e interpreta os estímulos oferecidos pelo meio e os registram no cérebro, permitindo assim, identificar objetos e acontecimentos significativos. Trata-se de um processo que se dá pelos órgãos de sentido. Kant (apud MARTIN, 1999:35) define a percepção com a formulação da seguinte frase: "nós não enxergamos as coisas como elas são e sim como nós somos". Pode-se dizer, então, que no processo de ensinoaprendizagem, ao se trabalhar qualquer conteúdo com o educando, a percepção destes estímulos estará embasada no contexto social onde ele está inserido, e que o auxiliou a construir sua bagagem de conhecimentos.

Maia (2012:95) afirma que:

a percepção depende dos estímulos externos que agem sobre os sentidos através do sistema nervoso, recebendo uma resposta que parte do cérebro, voltando a percorrer o sistema nervoso e chegando aos sentidos sob a forma de uma sensação, tais como um sabor, um odor, um cheiro, ou de uma associação de sensações, caracterizando uma percepção, como ver uma janela azul ou [ouvir uma música] (MAIA, 2012:95).

O autor supramencionado certifica que "a sensação é pontual e independente. A integração das sensações é realizada pela percepção a qual as unifica e organiza-as em uma síntese". Para Porchat (2005:76), a percepção de tais estímulos externos, podendo ser objetos, imagens, sons, etc., quando provocados, pode vir a se tornar uma representação dos mesmos através da comunicação.

\subsection{Representação Social}

Um dos grandes desafios para os estudiosos das ciências sociais é entender como o ser humano se relaciona e interpreta a realidade a sua volta em sua infinita busca de respostas, como ele apreende, distribui e assimila as várias explicações que lhe são fornecidas a fim de esclarecer suas dúvidas. Muitas explicações que são dadas aos questionamentos estão baseadas nas teorias do conhecimento científico e nas teorias do senso comum. O conhecimento baseado no senso comum se diferencia do conhecimento científico, tendo em vista este fundamentar-se na teoria científica que possui uma forte ligação com a pesquisa e tem um caráter provisório, ou seja, passível de mudanças. O senso comum, não se contrapondo ao conhecimento científico, se baseia no saber popular, ou seja, no pensamento que é recorrente à maioria, aquele que é passado de "um a um", e foi com relação a este tipo de conhecimento, que Serge Moscovici construiu a Teoria das Representações Sociais (TRS) (SANTOS; ALMEIDA, 2005:20).

Serge Moscovici estudou Psicologia na França em 1948, onde pesquisou e divulgou a Psicanálise e, em 1961, finalizou sua tese Psychanalyse Son Image, Son Public, propondo a TRS que remete ao conceito de representação coletiva do sociólogo alemão Émile Durkhein. Conforme menciona Santos (2010:2), Moscovici demonstra, em sua obra, os resultados de sua observação, nela procura compreender como a ciência da psicanálise, ao sair através da comunicação dos meios especializados no tema, ganha um 
outro conhecimento dentro dos grupos populares, ou seja, quando se tornava um conhecimento do senso comum.

De acordo com Santos e Almeida (2005:22) a TRS não estuda qualquer tipo de conhecimento do senso comum:

[...] mas a uma forma de conhecimento compartilhado, articulado que se constitui em uma teoria leiga a respeito de determinados objetos sociais. Por sua vez, falar na teoria das representações sociais é referir-se a um modelo teórico, um conhecimento científico que visa compreender e explicar a construção desse conhecimento leigo, dessas teorias do senso comum (SANTOS;ALMEIDA, 2005:22).

Conforme Jodelet, (2001:8) a Representação Social (RS) pode ser qualificada como sendo: “uma forma de conhecimento socialmente elaborada e compartilhada, que tem um objetivo prático e concorre para a construção de uma realidade comum a um conjunto social".

Sêga (2000:129) afirma que, para Jodelet, a TRS têm cinco divisões, sendo elas:

a) é sempre representação de um objeto;

b) tem sempre um caráter imagético e a propriedade de deixar intercambiáveis a sensação e a ideia, a percepção e o conceito;

c) tem um caráter simbólico e significante;

d) tem um caráter construtivo;

e) tem um caráter autônomo e criativo (SÊGA, 2000:129).

O conhecimento do senso comum é elaborado a partir de dois processos: ancoragem e objetivação. A ancoragem ocorre com a comparação de algum novo objeto ou ideia, a uma série de conhecimentos já existentes na bagagem de informações, ou seja, conhecimentos já familiarizados, e acabam adquirindo as propriedades desta categoria. Em síntese, o processo de ancoragem é adaptar algo estranho a um conjunto já familiar, através de simplificações ou até mesmo distorções, a fim de tornar confortável a prática de lidar com um novo conhecimento.

Já a objetivação trata da materialização do que é abstrato, este processo, pode ser dividido em duas fases, sendo elas, a materialização figurativa das abstrações, como os sentimentos ou ideias. Além da materialização figurativa, a objetivação assume uma materialidade quanto ao senso comum. Sucessivamente as RSs são inventadas e reinventadas, formando novos significados embasados em uma listagem pré-existente dos elementos, sendo que estes se tratam de uma miscigenação entre tradição e a inovação.

Baseados nos conhecimentos do senso comum, os conhecimentos científicos são apreendidos e remodelados pelo ser humano, formando um conhecimento leigo e voltado para seus questionamentos sociais. Desta forma, através de um instrumento de pesquisa qualitativa, buscou-se coletar as representações sociais da comunidade escolar em estudo, quanto aos possíveis efeitos alcançados a partir das atividades realizadas no Macrocampo Acompanhamento Pedagógico do Programa Federal Mais Educação, implementado na escola.

\section{Resultados e Discussões}

Trabalhar por uma educação ou reeducação, visando a pedagogia da complexidade, implica na valorização da sensibilidade, da criatividade, da criticidade e do pensamento reflexivo em busca da ética e de mudanças de condutas isolacionistas e utilitaristas. Esta é a base fundamental da Educação Ambiental, no entanto, colocá-la em prática ainda é um desafio para diversos atores envolvidos no processo educativo.

A Escola Muncipal de Ensino Fundamental Mascarenhas de Moraes - Polo, na qual foi realizada esta pesquisa, está localizada no interior do município de São Gabriel, Rio Grande do Sul, mais 
especificamente, na região de Catuçaba. Após desenvolver atividades do Macrocampo Acompanhamento Pedagógico, desenvolveu-se uma pesquisa de campo para verificar os efeitos resultantes de tais atividades.

Uma das atividades realizadas com os educandos do $3^{\mathbf{o}}$ ano, a fim de verificar e, ao mesmo tempo, incitar suas representações quanto à ligação com o seu contexto, foi a análise da letra da música "Eu sou do Sul", composição de Elton Saldanha, tocada com o violão e cantada em sala de aula. Os educandos sentaram-se em roda, cantaram juntos e, a cada verso, uma pausa era feita para que representassem a letra, por exemplo:

[...] Nascido entre a poesia e o arado

A gente lida com o gado e cuida da plantação

A minha gente que veio da guerra

Cuida dessa terra

Como quem cuida do coração [...]

Inicialmente foi perguntado a eles do que se tratava a palavra "arado", na canção. Uma das afirmações foi que servia para "virar a terra", então, novamente foi questionado o porquê precisaria "virar a terra", foi informado que o motivo seria para que a "parte de baixo" virasse "para cima". Diante desta hipótese trazida pelos educandos, foi problematizado o nome "arado", se teria alguma ligação com o "ar", frente a esta questão, os educandos demonstraram surpresa e deduziram que sim, pois a "terra que estava em baixo, agora estava em cima, pegando ar". Estas afirmações foram complementadas posteriormente com conhecimentos mais específicos, como: os raios solares, a fotossíntese, a atmosfera, os microrganismos, queimadas e cultura gaúcha, todas de forma adequada à faixa etária dos educandos.

Ao serem questionados sobre o que significava a palavra "poesia" mencionada na canção, alguns se referiram aos gaúchos cancioneiros, enquanto uma das crianças afirmou que: "poesia era música em silêncio". Diante destes relatos, pode-se perceber a criatividade e a sensibilidade aflorada nas crianças que, a partir de uma música que aborda dentre tantos outros temas, como Ciências e História, conseguem representar além do que está a sua frente (Figura 1).

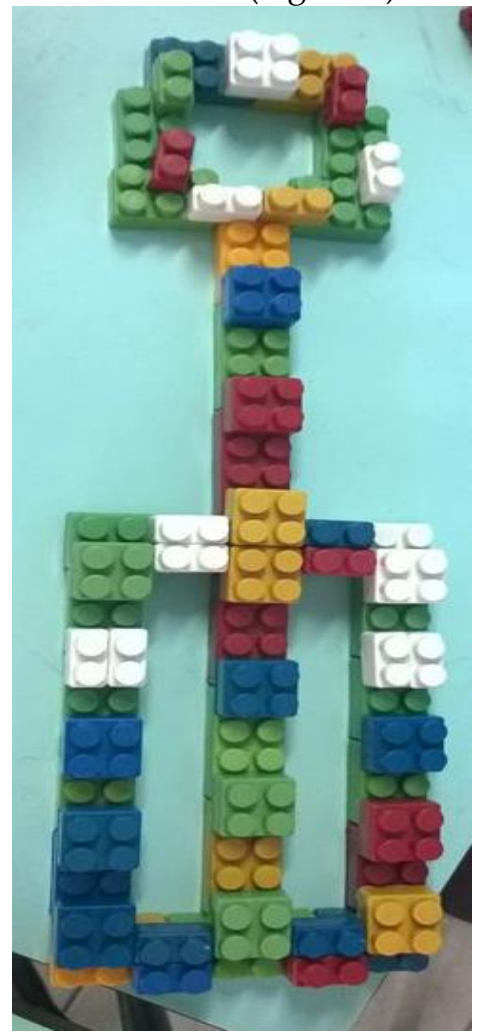

Figura 1: Representação de uma guitarra feita por uma estudante do $1^{\circ}$ ano 
Outro exemplo de atividade realizada na Escola foi uma complementação sobre o tema fotossíntese. Após trabalhar conceitos básicos sobre o processo da fotossíntese, com a utilização de vídeos e documentários, buscou-se elaborar um painel confeccionado pelos educandos, a partir da coleta de restos de folhas (o que já havia feito fotossíntese) e resíduos secos (lixo) encontrados na escola, para posteriormente realizarem uma análise e comparação do resultado (Figura 2). Nesta atividade pode-se perpassar temas referentes à Ciências e respeito à Escola e seu entorno.

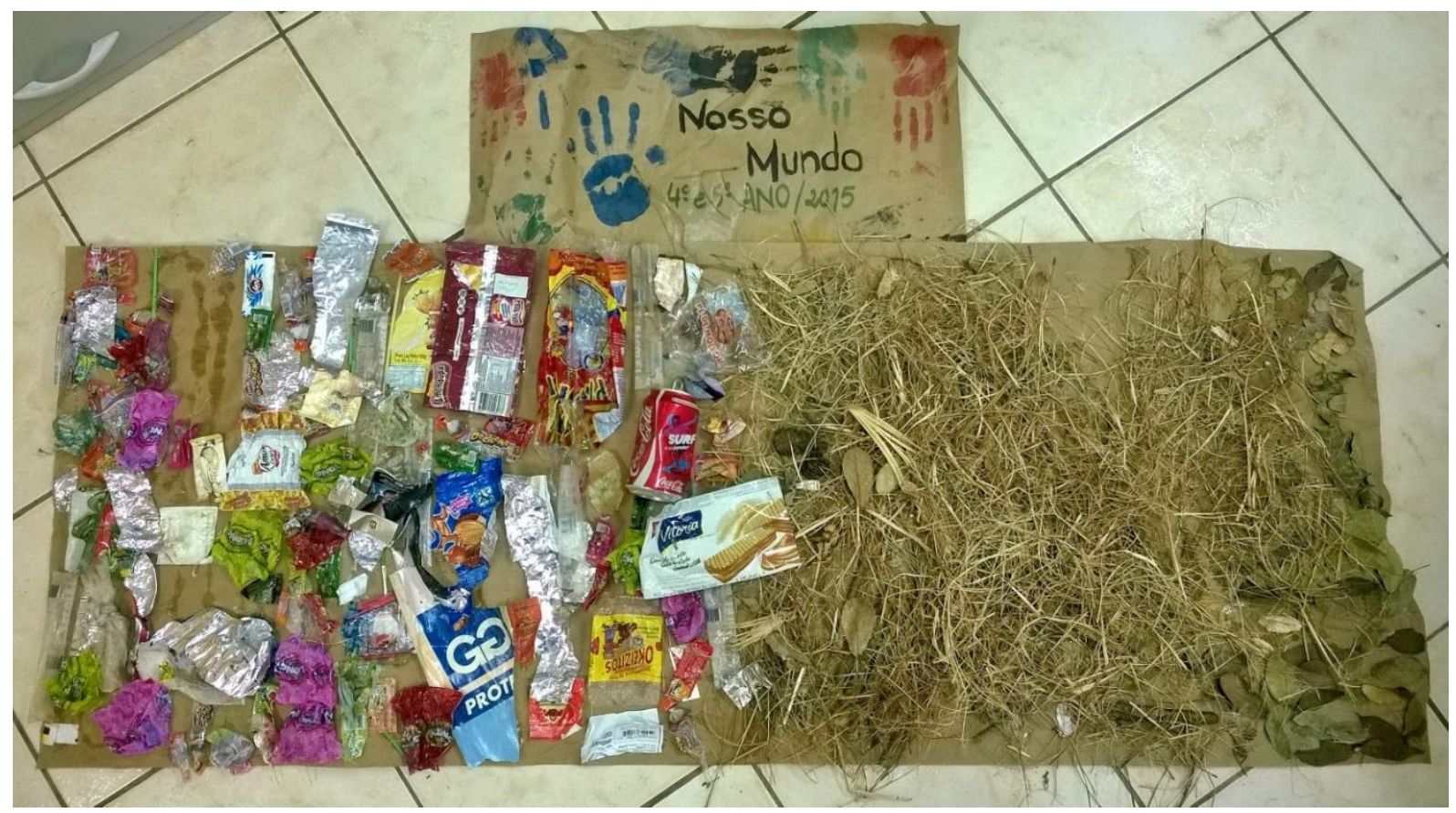

Figura 2: Trabalho desenvolvido pelos alunos do $4^{\circ}$ e $5^{\circ}$ anos da Escola

Em outra oportunidade, trabalhou-se com músicas em Espanhol, uma delas chamada "Rie Chinito" (Dolo e Maju), gravada pelo Grupo Perotá Chingó, em que os educandos ouviram-na com os olhos fechados, e após, representaram seus sentimentos e quais imagens foram surgiram em sua mente, para posteriormente, traduzi-la e realizar uma comparação entre as representações manifestadas. Outra música foi uma composição gravada por Mercedes Sosa chamada "Todo Cambia" (Julio Numhauser) . 


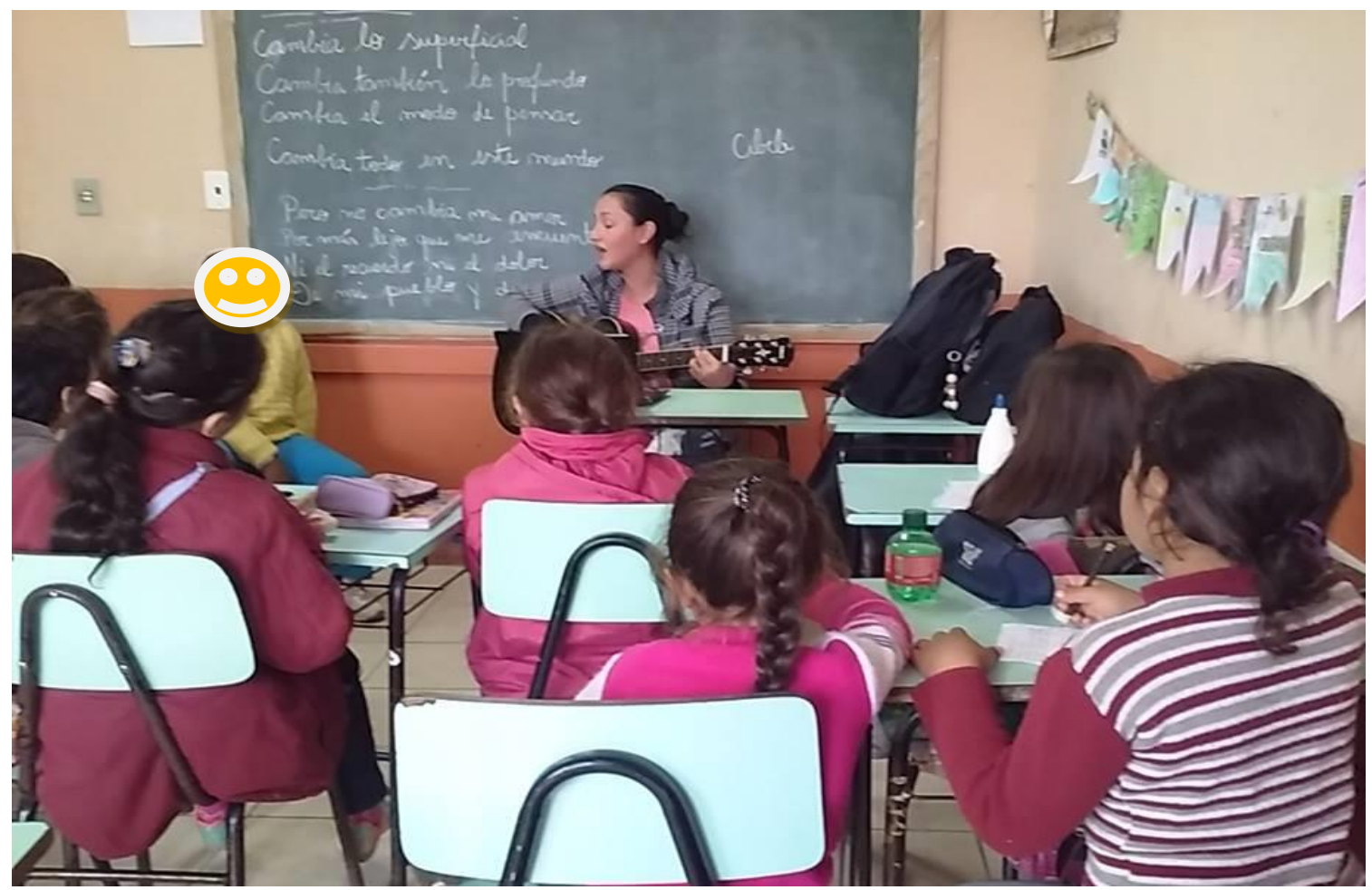

Figura 3: Atividade realizada com educandos do $2^{\underline{ }}$ ano

A primeira música carrega informações que auxiliaram os educandos a lembrarem de montanhas e vulcões, demonstrando uma forte demanda pelo assunto, também, devido ao vulcão Calbuco, localizado no Chile, que havia entrado em erupção na semana em que as atividades estavam sendo realizadas. Este tema foi trabalhado, também, e diversas problemáticas foram feitas a respeito, como a sua localização, como formam-se montanhas e vulcões, do que a lava é composta e, ainda, sobre os dinossauros e a respeito da evolução.

Diante da demanda sobre o tema, uma das aulas foi dedicada aos fósseis de dinossauros encontrados na região onde está localizada a Escola, o Tiarajudens excentricus e o Pampaphoneus biccai, bem como aqueles fósseis encontrados na região central do Rio Grande do Sul.

Através da análise de conteúdo coletado nas entrevistas, constatou-se o interesse dos estudantes quanto às temáticas mencionadas acima, pois dentre as treze ideias relacionadas às atividades que mais haviam gostado, foi a que apresentou maior frequência (4 citações), podendo ser confirmada a partir da descrição das ideias de alguns estudantes e pais:

Eu acho que deveria dar mais coisas de Dinossauros.

Ter aulas de ciências e de dinossauros.

A atividade que eu mais gosto é de ciências, Espanhol e sobre os dinossauros.

Eles falam sobre aula de dinossauro.

Durante algumas aulas, percebeu-se manifestações homofóbicas, motivando um novo debate e o planejamento de uma aula baseada na diversidade sociocultural, com vídeos que abordam sobre este e outros temas, como a tolerância e a inclusão social. A proposta inicial foi de compreender sobre a "História do Funk", abordadando a história e as influências socioculturais de outros países neste gênero musical, que é apreciado por alguns estudantes da Escola, principalmente do $4^{\circ}$ e $5^{\circ}$ anos. Nesta atividade, a EA deu todo o embasamento às discussões que surgiram durante a aula, visto que tratavamse de temas que relacionavam as diferenças e as causas da crise social existente, ao proporcionar o contexto em que algumas letras de músicas deste gênero foram compostas, além de levar outras músicas 
ao conhecimento dos educandos, problematizando o preconceito e como ele pode estar relacionado à crise social e, consequentemente, à crise ambiental.

Algumas atividades musicais basearam-se em percussões corporais através do estudo das nomenclaturas musiciais do corpo, em que os educandos trabalharam com a lateralidade, concentração, coordenação motora e cooperação de uns com os outros.

Nas festividades juninas, trabalhou-se com as mudanças ocorridas no tempo e ações que, feitas no passado, tenham influenciado no presente, através da comparação entre três gravações diferentes da música "Cai, cai balão"(folclore), uma de Aurora Miranda e Francisco Alves, feita em 1933, outra gravação desta mesma composição, mas com caráter infantil e outra versão da mesma música, gravada pelo grupo vocal "Nós em Voz", com arranjos vocais e melodias diferentes. Na ocasião, foi trabalhada com os educandos a questão social da responsabilidade sobre ações e suas consequências, abordando sobre a ilegalidade de soltar balões nestas e outras festividades. Na oportunidade, foram confeccionados, pelos estudantes, balões de papéis estilo "origami", que não precisam da utilização do fogo. Ao visualizarem um vídeo que mostrava uma pipoca em "slow motion", um dos estudantes exclamou a seguinte frase: "Sôra, nós mudamos como a pipoca!". Com este vídeo, foi abordado de forma simplificada a respeito da cultura nordestina, de onde surgiu esta cultura, e o amido presente no milho, ou seja, conhecimentos a respeito de História, Geografia e uma pequena base sobre Química.

Pode-se verificar os reflexos desta atividade, a partir do relato de uma Professora voluntária:

Os alunos chegam a aula relatando as suas experiências, olhos brilhantes e aguçados, interessados em saber mais e preocupados com suas ações que interferem na sobrevivência do planeta fazendo co-relação das ações do passado no hoje e no futuro.

Muitas atividades foram complementadas com os jogos educativos do Programa Mais Educação, bem como, jogos em sala de aula, em que os conteúdos curriculares trabalhados com as Professoras da Escola, eram vistos de forma lúdica e diferente, a fim de auxiliar na significação do saber adquirido pelos educandos.

Os resultados apontaram, quanto à mudança de comportamento, maior frequência de ideias relacionadas à melhoria da interatividade e convívio social (9 citações) com a família (4 citações), com os colegas, e com a comunidade escolar, bem como, aquelas que apontam um melhor rendimento escolar (5 citações), conforme pode-se verificar em alguns relatos representandos por alguns voluntários:

[...] ela ficou mais interessada com os estudos e seu comportamento melhorou muito em casa e com seus colegas.

Torna-se visível dia após dia o crescimento intelectual, bem como, a capacidade de desenvolvimento do raciocínio e facilidade na interpretação de ideias.

Tenho percebido mudanças boas.

Antes ele chegava em casa e só ficava jogando "prei", e não falava nada. Agora ele chega feliz contando da mais educação. Que ele está gostando muito.

Ele chega muito fasero da escola e ele conta que aperde mutas cousa.

Percebo que ela quer fazer tudo o que foi realizado na escola, quer fazer tudo em casa de novo. 
Pode-se perceber que os efeitos atingidos pelas atividades realizadas no Macrocampo Acompanhamento Pedagógico, não se restringiram tão somente à melhoria intelectual dos estudantes, pois verifica-se, através dos relatos abaixo, que também influenciaram no relacionamento interpessoal, aumentando a interação e aproximação com a família e com os colegas.

Os alunos certamente adquiriram o hábito de interação com os demais, melhorando consideravelmente a socialização na comunidade escolar.

Como a minha turma sempre foi muito agitada, deu para perceber que eles estão bem mais calmos, mais interessados pelas aulas, estão mais participativos.

Eles passaram a se respeitar mais, houve mais aproximação entre eles.

Eles estão mais atentos e o raciocínio bem mais rápido.

[...] Pode notar que eles superaram algumas dificuldades que eles apresentavam e o interesse nas aulas aumentou.

O rendimento melhorou, os alunos estão mais atentos ao fazer análise e interpretação de textos.

A disciplina melhorou.

Melhorou a interatividade e o convívio social.

Estão almoçando mais.

A partir da análise de conteúdo das ideias manifestadas pelos voluntários da comunidade escolar, percebeu-se que 3 manifestações de ideias foram contrárias das demais, afirmando não ter notado mudanças no comportamento dos estudantes, sendo que uma destas citações, é de uma das 7 professoras da Escola, que afirmaram terem notado aumento no rendimento escolar (5 citações) e no interesse pelos estudos (4 citações), conforme já mencionado acima.

Verifica-se que de 8 ideias a respeito das aulas realizadas no Macrocampo, 7 foram consideradas avaliações positivas, ocorrendo maior frequência daquelas referentes às aulas terem sido muito boas, bem como, àquelas ideias que indicaram que os respondentes gostaram das aulas e que não tinham o interesse de mudá-las em nada. Algumas destas representações são também, de pais, mães e responsáveis, que foram relatadas a partir de comentários dos próprios educandos, demonstrando aumento na aproximação destes com seus familiares.

Pode-se perceber também, a demanda dos educandos quanto às atividades relacionadas à música, Espanhol, ciência e de brincadeiras no geral, estas representações foram motivadas devido às aulas trabalhadas com eles, pois muitas vezes, a música deu embasamento para diversos diálogos e atividades realizadas em sala de aula, seja a respeito do próprio idioma em espanhol ou através de traduções para o português, sendo que, na oportunidade, regras ortográficas eram inseridas e trabalhadas através de jogos e brincadeias. Os aspectos científicos também foram trabalhados através da música, como exemplo, a canção chamada "Eu sou do Sul", já relatada neste trabalho.

As representações quanto às categorias "aulas da Professora Cibele" e "Professora Cibele", carregam informações consideradas positivas, afirmando haver respeito dos educandos com a Professora, apresentando a mesma frequência. As ideias relacionadas ao aprender e fazer coisas boas, bem como, aquelas referentes a gostar da aula da Professora, também tiveram a mesma frequência, sendo que, a categoria "Professora Cibele", teve 6 ideias também consideradas positivas. 
Muitas ideias manifestadas pelos respondentes, tiveram correlações umas com as outras, sejam entre professores e funcionários, funcionários e pais, pais e professores, com respostas similares a respeito das mudanças de comportamento percebidas nos estudantes. Estas representações demonstram a eficácia de trabalhar de forma interdisciplinar, sendo que, neste trabalho, a Música e a Educação Ambiental deram todo o embasamento das ações realizadas no Macrocampo Acompanhamento Pedagógico.

\section{Considerações Finais}

O ato de educar exige do educador imparcialidade, superação e quebra de paradigmas e valores e, muitas vezes, isso requer compreender novos conhecimentos e metodologias que exijam deste profissional um maior empenho ao desenvolver suas atividades em sala de aula.

Neste trabalho, a Educação Ambiental e a Música foram tidas como base das ações realizadas em aula e, de forma interdisciplinar, estiveram presentes em diversas atividades realizadas com os educandos, ao perpassarem os conteúdos curriculares trabalhados pelas educadoras da escola.

Através da Educação Ambiental objetivou-se auxiliar os educandos a desenvolverem comportamentos críticos perante várias culturas impostas pelo modelo civilizatório contemporâneo e, ao mesmo tempo, compreender a complexa gama de relações existentes no meio ambiente onde o ser humano está inserido, entendendo que sempre haverá consequências em suas ações.

A Música esteve presente em diversas situações como ponto de convergência entre vários temas e ao mesmo tempo, através da sensibilização, auxiliou o educando no processo de assimilação de novas informações, visto que os códigos musicais ao ativarem ambos os hemiférios cerebrais, tornaram os neurônios receptivos a adquirirem novos conhecimentos de outros órgãos dos sentidos.

Os efeitos das atividades e ações do Macrocampo Acompanhamento Pedagógico, realizadas nos anos iniciais do ensino fundamental, refletiram em mudanças significativas no comportamento dos educandos, que se traduziram em práticas pessoais no dia a dia, como no rendimento escolar e no aumento da socialização entre eles e os demais agentes envolvidos.

Torna-se visível a necessidade de ações que estejam voltadas à forma lúdica de ensinar, bem como, da utilização de metodologias inovadoras que busquem auxiliar no processo de ensino-aprendizagem, auxiliando o educando, não somente a compreender teorias e conteúdos em sala de aula, como se fosse o produto final do processo educativo, mas também, como utilizá-las em seu contexto social.

\section{Referências}

BARDIN, L. Análise de conteúdo. Lisboa: Edições 70, 1995.

BRASIL.. Parâmetros curriculares nacionais: meio ambiente/saúde. Brasília: Secretaria de Educação Ambiental, 1998.

GRUN, M. Ética e educação ambiental: A conexão necessária/ Mauro Grun. - Campinas, SP: Papirus, 1996.

GUIMARÃES, M. A dimensão Ambiental na Educação. 2 ed. São Paulo: Papirus, 2007.

JODELET, D. (org.), As Representações Sociais. Rio de Janeiro: Editora da UERJ, 2001.

LEFF, E. Educação ambiental e desenvolvimento sustentável. In: REIGOTA, M. (org.). Verde cotidiano: o meio ambiente em discussão. Rio de Janeiro: DP\&A, 1999. 
LEFF, E. Saber ambiental: sustentabilidade, racionalidade, complexidade, poder. Trad. Lúcia Mathilde Endlich Orth. Petrópolis, RJ: Vozes, 2001.

LEFF, Enrique. Complexidade, interdisciplinaridade e saber ambiental. Olhar de professor, Ponta Grossa, v.14, n. 2, 2011.

MAIA, W. M. Percepção e inteligência artificial - Conceitos, considerações e arquitetura. São Paulo: Biblioteca24horas, 2012.

MALHOTRA, N. Pesquisa de marketing: uma orientação aplicada. 4. ed. Porto Alegre: Bookman, 2006.

MARTIN, A. S. K. Introdução à Psicologia. São Paulo: Pioneira Thomson, 1999.

MUSZKAT, M.; CORREIA, C.M.F.; CAMPOS, S.M. Música e Neurociências. Revista de Neurociências, v. 8, n. $2,2000$.

PORCHAT, P. Freud e o teste de realidade. São Paulo: Casa do Psicólogo, FAPESP, 2005.

PORCHER, L. Educação artística - luxo ou necessidade? São Paulo: Summus Editorial, 1982.

SANTOS, M. de F. de S.; ALMEIDA, L. M. de (Orgs.), L. M. Diálogo com a Teoria das Representações Sociais. Recife: Editora Edufal, 2005.

SCHAFER, R.M. O ouvido pensante. Trad. Marisa Trench de O. Fonterrada, Magda R. Gomes da Silva, Maria Lucia Pascoal. São Paulo: Fundação Editora da UNESP, 1991.

SÊGA, R. A, O conceito de representação social nas obras de Denise Jodelet e Serge Moscovici. Revista anos 90 - Revista do Programa de Pós-Graduação de História, v. 8, n. 13, 2000.

SEKEFF, M. de L. Da música: seus usos e recursos. São Paulo: Editora: UNESP, 2002; 2007.

TITTON, M.B.P.; XAVIER, M.L.M.F.; PACHECO, S.M. (orgs.). Caderno Pedagógico do Macrocampo Acompanhamento Pedagógico. Brasília: Ministério da Educação, 2011. 117 p. Disponível em: http://portal.mec.gov.br/index.php?option=com_docman\&task=doc_download\&gid=8206\&Itemid=. Acesso em: 20 ago. 2015.

TRISTÃO, R. M.; PEDERIVA, P. L. M. Música e Cognição. Ciências \& Cognição; ano 3, v. 09, 2006. Disponível em http://www.cienciasecognicao.org/revista/index.php/cec/issue/view/24. Acesso em: 15 ago. 2014. 